\title{
The psychological mechanisms of persuasive impact from narrative communication
}

\author{
Lijiang Shen, Pennsylvania State University, Department of Communication Arts \& Sciences* \\ Suyeun Seung, University of Georgia, Department of Communication Studies \\ Kristin K. Andersen, University of Georgia, Department of Communication Studies \\ Demetria McNeal, University of Georgia, Department of Communication Studies \\ ${ }^{*}$ Corresponding author: lus32@psu.edu
}

\begin{abstract}
This paper develops and tests a comprehensive psychological model of how narrative messages persuade. In this model, perceived realism and perceived similarity are considered as the antecedents of narrative engagement variables. There are three forms of narrative engagement, transportation, identification, and parasocial interaction, which are conceptualized as the primary mediating mechanisms. Message elaboration and psychological reactance are proposed as the secondary mediating mechanisms. A web-based study $(N=374)$ was conducted to test this complex model. Four video clips on sexual health topics from wellknown television series were used as the stimuli. Structural Equation Modeling (SEM) analyses showed that perceived realism and perceived similarity were antecedents of narrative engagement. There was conceptual overlap between the narrative engagement variables, but they remained distinct from each other. There was no unique effect on persuasion from parasocial interaction. There was evidence for direct effects on persuasion from transportation and identification, as well as their indirect effects through reducing psychological reactance. However, message elaboration was found to be negatively associated with message perception. Implications for narrative communication in general and future studies were discussed.
\end{abstract}

\section{Keywords}

narrative communication, transportation, identification, parasocial interaction, elaboration, reactance, persuasion

\section{Introduction}

There has been increasing interest in the role of narratives in persuasion and health communication. Narratives can be defined as symbolic representation of cohesive and coherent events with an identifiable structure (Bilandzic \& Busselle, 2013), which are bounded in space and time, and contain implicit or explicit messages about the topics being addressed (Kreuter et al., 2007). Narrative communication can be in the form of literature, storytelling, entertainment education, journalism, testimonials, etc. Not all narratives are persuasive in nature. Narratives in the forms of literature and storytelling have little to do with persuasion due to the lack of both persuasive advocacy and intention. Narratives in entertainment can be strategically designed such that health and educational information can be embedded in the story plots, with implicit intent to persuade. On the other hand, the persuasive arguments and advocacy in commercial advertisements as well as public service announcements (PSAs), which are with clear intent to persuade, can be presented in the form of narratives.

Therefore, narrative communication can vary in two dimensions: 1 ) proportion of entertainment vs. educational/health information, and 2) intent to persuade ranging from implicit to explicit. Narrative persuasive messages are therefore broader than, and distinct from narrative evidence (i.e., personal testimonies) as contrasted with statistical evidence in the study of persuasion. Recent meta-analyses (Braddock \& Dillard, 2016; Shen, Sheer, \& Li, 2015; van Laer, Ruyter, Visconti, \& Wetzels, 2014) have confirmed the pos- 
itive impact of narratives on persuasion outcomes including beliefs, attitudes, and intentions.

Lately the focus of attention in narrative communication research has shifted to the psychological mechanisms that underlie the impact of narrative messages (Bilandzic \& Busselle, 2013). Researchers have investigated a host of mechanisms underlying narrative effects, including story appraisal (i.e., how representation of stories or story kernels are processed, Berger \& Lee, 2011), transportation (i.e., being immersed in the narrative, Green \& Brock, 2002), and identification (i.e., perspective-taking, experience sharing, and connecting with the characters, Cohen, 2001). Bilandzic and Busselle (2013) identified the most convincing mechanisms as the ability of narrative messages to minimize various forms of resistance by making the intent to persuade more implicit through para-social interactions with the characters, and through the audience's liking or identification with the characters. In their review of the literature, Bilandzic and Busselle called for more research on these underlying psychological mechanisms to better understand the precise nature and forms of narrative engagement as the mediators of narrative effects.

Coming from different theoretical perspectives, the majority of existing studies on narrative communication have investigated only some of these identified mechanisms as causal antecedents of narrative effects. While such studies have advanced scholars' understandings of why narrative messages are persuasive, they are also with limitations. First, by leaving out some other potential mechanisms, the unique contribution of each factor under investigation cannot be assessed because the different mechanisms tend to be associated with each other due to conceptual overlap. Second, these overlooked factors constitute potential alternative explanations; hence, internal validity might be questionable when they are not controlled for in data analyses. Third, only studying some of the mechanisms gives a partial picture, which would sometimes cast doubts, rather than shed light on the nature and form of the underlying mechanisms. This is due to the issue of endogeneity, which occurs when potential predictors of the outcome variable are omitted in data collection and/ or analyses, leading to biases and fallacies in causal inferences (Antonakis, Bendahan, Jacquart, \& Lalive, 2010). The primary goals of this paper were to answer the call from Bilandzic and Busselle (2013), and to conduct a more comprehensive study of the identified psychological mechanisms of narrative communication, situated in a nomological network that consisted of their antecedents and outcomes. The antecedents would be the combination of message features and audience characteristics (e.g., perceived realism and similarity between characters and viewers). We propose that upon exposure to narrative messages, individuals are engaged in various forms of narrative engagement that constitute the primary mechanisms underpinning narrative persuasion (i.e., including identification, transportation, and parasocial interaction), which have direct effects on persuasion outcomes. In turn, these narrative engagement variables also have indirect effects on persuasion via message elaboration and (overcoming) resistance, which form the secondary mechanisms of narrative effects.

\section{A conceptual model of narrative persuasion effects}

\subsection{Antecedents of narrative persuasion}

There are many different approaches to the nature and forms of narrative engagement. Despite all differences, there is scientific consensus on their antecedents. Scholars agree that two factors play a crucial role: Perceived realism and similarity between the receiver and characters portrayed in the narrative. Existing conceptualizations of the perceived realism construct suggest a multi-dimensional structure (Hall, 2003; Shapiro \& Chock, 2003). Cho, Shen, and Wilson (2014) provided some empirical evidence for the multi-dimensionality. Existing theories and empirical evidence suggest that realism is associated with various forms of narrative engagement. Realistic 
media representations that are authentic and true to real life are generally more engaging than nonrealistic ones (Busselle \& Bilandzic, 2008). Realistic portrayal of characters and events might influence narrative engagement in multiple ways. First, they can serve as exemplars, which facilitate processing of media information as well as identification with the message (Zillmann, 2002). Second, realistic messages can activate empathic responses, in which recipients share the perspective and emotions of, and identified with, the characters (Campbell \& Babrow, 2004; Shen, 2010). Third, realistic media messages also result in more transportation, which is a state of immersion into the narrative consisting of attention, imagery, and feelings (Green, 2004; van Laer et al., 2014). Fourth, there was also a positive association between realism and parasocial relationships (Schiappa, Allen, \& Gregg, 2007). Results from Cho et al. (2014) showed that the impact from the sub-dimensions of perceived realism might be variable; however, as a whole, they had a joint impact on narrative engagement in the form of identification and emotional involvement, and message evaluation. Hence, it was predicted that:

$\mathrm{H1}$ : Perceived realism is positively associated with narrative engagement including: H1a) identification, H1b) transportation, and H1c) parasocial interaction.

Similarity (between the viewer and characters) is believed to be another determinant of narrative engagement. What is similar between the audience and the protagonists in the message is not limited to their appearance or demographic information (Oatley, 1996), but also includes experience, past and present. Common and shared experiences make it easier for the recipients to empathize with the communicator/characters, to play act, and to have an imaginative and vicarious experience. There is evidence that similarity leads to identification (Fisher, 1998; Murphy, Frank, Chaterjee, \& Baezconde-Garbanati, 2013), liking (Selfhout, Denissen,
Branje, \& Meeus, 2009), parasocial interaction (Rubin \& McHugh, 1987; Turner, 1993), transportation, and stronger emotional involvement (Murphy et al., 2013; van Laer et al., 2014). Moreover, similarity also increases empathic responses such as behavior mimicry (Gueguen \& Martin, 2009), contagious yawning (Campbell \& de Waal, 2011), and neural correlates of empathy (Hall \& Woods, 2006). Along this line of argument, it was predicted that:

H2: Perceived similarity is positively associated with narrative engagement: H2a) identification, H2b) transportation, and $\mathrm{H} 2 \mathrm{c}$ ) parasoical interaction.

\subsection{Mediating variables of narrative persuasion}

Multiple psychological factors have been proposed as the mechanisms that underlie the impact from narrative communication. Recent reviews (Bilandzic \& Busselle, 2013; Kreuter et al., 2007) concurred upon the following: transportation, identification, parasocial interaction, message elaboration, and reduction of resistance. Transportation, identification, and parasocial interaction are mechanisms in which an audience member connects to the narrative and characters (Green, 2007). These three forms of engagement involve characters, and distinguish processing of narrative messages from non-narrative ones; hence, they are considered as the primary mechanisms. Message elaboration and resistance reduction are the immediate consequences of the primary mechanisms in narrative processing, but not unique to processing of narrative messages; therefore, they are considered as the secondary mechanisms. Combined, these factors are the immediate causal antecedents to persuasive outcomes from narrative messages.

Transportation. Through transportation individuals can take part in the narrative as if they were present in the depicted world. Once transported, the message recipient is immersed in the narrative, and temporarily engages in an experience foreign or unfamiliar from the norm. During this experiential state, a person has de- 
creased self-awareness and converges to the story, fully focusing on the narrative itself (Appel \& Richter, 2010; Green \& Brock, 2000). They concentrate on the events of the story and focus all mental capacities on the current affairs taking place in the narrative (Green \& Brock, 2000). Since the transportation process causes an individual to converge with the narrative, the viewer's beliefs become more susceptible to information presented in the narrative (Appel \& Richter, 2010); hence, transportation leads to more persuasion and/or media effects (Escalas, 2004a; Green \& Brock, 2000; Green et al., 2004). The meta-analysis by van Laer et al. (2014) confirmed the positive impact from transportation on such outcomes as belief, attitude, and intention. Therefore, it was predicted that:

H3a: Transportation has a positive and direct effect on persuasion.

Transportation can also facilitate persuasion indirectly. Transportation is believed to influence cognitive responses to the narrative. Cognitive responses to the narrative might be analyzed along two dimensions: target and valence. Cognitive responses could be directed at the entertainment information (i.e., the story), or the education information (i.e., the embedded advocacy) (Fisch, 2000). They can be favorable (i.e., positive) thoughts, neutral (i.e., non-evaluative) thoughts, or counter-arguments (i.e., negative) (Cacioppo \& Petty, 1981). The Extended ELM model (Slater \& Rouner, 2002), the Transportation-Imagery-Model (Green \& Brock, 2000), and the Entertainment Overcoming Resistance Model (EORM, Moyer-Gusé, 2008; Moyer-Gusé \& Nabi, 2010) all suggest that once transported, individuals would perceive the narrative as more relevant and related to their own experiences/lives, which, according to the dual process models (Petty \& Cacioppo, 1986; Chaiken, Liberman, \& Eagly, 1989), would increase narrative-related and positive responses. Zillmann's (2002) exemplification theory also suggests that the characters and their experiences presented in the narrative constitute exemplars, which are more elemental and concrete rather than complex and abstract; hence, they are more attention-grabbing and processed in a more effortful manner than a non-narrative absent of exemplars. In other words, they result in enhanced message elaboration. On the other hand, since the message recipients would be preoccupied with processing the narrative, they would be less able and less motivated to scrutinize; hence reduction in counterarguments.

Empirical evidence regarding the impact of transportation on cognitive responses has been rather mixed. Results from Escalas (2007) showed that transportation actually reduced elaboration in that the persuasive impact of weak arguments was no different from strong arguments. On the other hand, Krakowiak and Oliver (2012) found transportation led to a higher level of cognitive enjoyment. The pattern was similar for counterarguments. Green and Brock (2000) found that transportation reduced scrutiny during the task of identifying/circling false notes. There was also such evidence from thought-listing data (Escalas, 2004a). On the other hand, Moyer-Gusé and Nabi (2010) found that transportation actually increased counterarguments measured by self-report Likert scale data. Such inconsistent findings might have been due to the nuances in the operationalization of message elaboration and counterarguments. Taking care of such nuances, van Laer et al. (2014) suggested that it might be more appropriate to separate cognitive responses related to the story versus the critical responses. Their meta-analyses showed that transportation had a positive and significant impact on narrative-related cognitive thought, but a significant negative impact on critical thought (i.e., scrutiny). Based on both theory and empirical evidence, it was predicted that:

H3b: Transportation has an indirect positive effect on persuasion by reducing counterarguments.

H3c: Transportation is positively associated with message elaboration, which facilitates persuasion. 
Identification. Identification as a narrative mechanism involves understanding the narrative, adopting the characters' perspective, following their experiences, and relating to and connecting with the characters (Cohen, 2001). It facilitates a vicarious and imaginative experience of what happened to the characters (Bilandzic \& Busselle, 2013). There are multiple ways in which identification facilitates narrative effects. First, Social Cognitive Theory (Bandura, 2001) suggests that identification offers an opportunity of vicarious learning and thus increases perceived self-efficacy. Second, identification is considered as one of the forms in which opinion change occurs (Kelman, 1961). Third, identification mediates celebrity effects and media effects in general (e.g., Basil, 1996; Cohen, 2001; Hoffner, \& Buchanan, 2005; Igartua, 2010; Moyer-Gusé, Chung, \& Jain, 2011). Therefore, it was predicted that:

H4a: Identification has a positive and direct effect on persuasion.

Like transportation, identification can also have an indirect effect on persuasion outcomes. As identification "internalizes" the narrative, audience members tend to perceive the message as more relevant and related to their own lives and experiences (Cohen, 2001; Slater \& Rouner, 2002). That is, identification increases personal involvement, which stimulates message elaboration (see Escalas, 2007). There has been empirical evidence for this impact of identification on message elaboration (Escalas, 2004b; Igartua, 2010). Internalization of the narrative suggests that the receivers are more likely to understand and adopt the perspective, arguments, evidence, and logical reasoning presented in the narrative. In other words, the receivers' cognitive responses will be positive in valence and they tend to agree with, and yield to the narrative. That is, the cognitive elaboration associated with identification tends to be positive in valence (Escalas, 2004b; Igartua, 2010). Such positive cognitive responses reduce biased processing and decrease counterarguments (Dal Cin,
Zanna, \& Fong, 2004). Along this line of argument, it was predicted that:

H4b: Identification has an indirect positive effect on persuasion by reducing counterarguments.

H4c: Identification is positively associated with message elaboration, which facilitates persuasion.

Parasocial Interaction. Parasocial interaction refers to the interaction between an audience member and the characters in the narrative, which forms a pseudo-relationship (Moyer-Gusé, 2008). Such pseudo-relationships might have similar features of real ones (e.g., voluntary entry, companionship, and social attraction, Perse \& Rubin, 1989), but they are not reciprocal, and might just be wishful (e.g., Hoffner \& Buchanan, 2005). Due to social attraction (Perse \& Rubin, 1989), attachment (Cohen, 2001), and affective disposition (i.e., the disposition toward characters through moral judgment of motives and conduct, Zillmann \& Knobloch, 2001) involved in a parasocial relationship, elevated parasocial interaction is believed to have a positive impact on narrative effects (see Schiappa, Allen, \& Gregg, 2007). Hence it was predicted that:

H5a: Parasocial interaction has a positive and direct effect on persuasion.

The extant theories and models of narrative communication do not offer clear guidance regarding the impact of parasocial interaction on message elaboration. On one hand, since the focus of parasocial interaction tends to be the characters in the narrative, rather than the content, it can be expected that parasocial interaction would not result in processing of evidence, argument, or logical reasoning (i.e., high message elaboration), instead, features of the characters will be processed, which tends to be superficial and less effortful. There is evidence that audience member's connecting with and relating to the characters produce more associative processing (i.e., developing and maintaining 
cognitive connections between objects) and reduced message elaboration (e.g., Shen, 2010). On the other hand, the affective, cognitive, and behavior processes involved in parasocial interaction including attention, comprehension, knowledge activation, evaluation, and social comparison can be quite intense (Schramm \& Hartmann, 2008). Consequently, parasocial interaction should increase message elaboration. Regardless of the depth of message processing, due to the social attraction, attachment, and affective disposition, such cognitive responses tend to be positive in valence. Therefore, we advanced a hypothesis:

H5b: Parasocial interaction has an indirect positive effect on persuasion by reducing counterarguments.

Against this background, a research question arises:

RQ: What is the impact of parasocial interaction on message elaboration?

The nature of narrative communication and the various forms a narrative message might take mean that persuasion intention is not always present or explicit in the message. Regardless of the narrative form or explicitness of persuasion intent in the message, scholars have proposed that narratives help overcome resistance (Dal Cin et al., 2004; Moyer-Gusé, 2008; Moyer-Gusé \& Nabi, 2010). In addition to more implicit intent to persuade, various forms of narrative engagement tend to decrease perceived threat to freedom, hence mitigate reactance (J. Brehm, 1966; S. Brehm \& J. Brehm, 1981). First, to the degree individuals are transported into the narrative, they tend to internalize the information and arguments presented because they are now part of the narrative. As a result, individuals are less likely to experience less perceived control or manipulation. Second, identification with the characters and the narrative means that individuals would consider the information as more relevant and internal rather than external; which also reduces perceived threat to freedom and reactance (Steensma \& Erkel, 1999). Third, due to social attraction and affinity, parasocial interaction with characters makes the message seem less authoritative, less controlling, and more acceptable (Moyer-Gusé \& Nabi, 2010).

The EORM model (Moyer-Gusé, 2008; Moyer-Gusé \& Nabi, 2010) suggests that there are three forms of resistance: reactance, counterarguments, and reduction in perceived vulnerability to a health risk. Counterarguments are considered as part of the reactance construct (e.g., Dillard \& Shen, 2005), which was confirmed by the obtained reduced model in Moyer-Gusé and Nabi (2010). In the realm of risk communication, perceived vulnerability might be conceptually closer to risk perception itself (i.e., persuasion outcome), rather than (reduced) resistance to persuasion. The relevance of perceived vulnerability to a risk might be further reduced beyond the scope of narrative risk communication. Along this line of argument, we focused on psychological reactance operationalized as the combination of counterarguments and anger. Therefore, the following hypothesis was predicted:

H6: Narrative engagement variables are negatively associated with psychological reactance.

Overall, we advanced a model where features of narrative messages function as antecedents to the primary mechanisms (identification, transportation, and parasocial interaction), which have direct and indirect effects (through the secondary mechanisms of message elaboration and reducing resistance) on persuasion outcomes. Since counterarguments can be considered as a form of resistance, it is subsumed by the construct of resistance/ reactance. Figure 1 presents a conceptual diagram of the model that summarizes the hypotheses and the research question. 
Figure 1: Conceptual model for the mechanisms underlying narrative effects

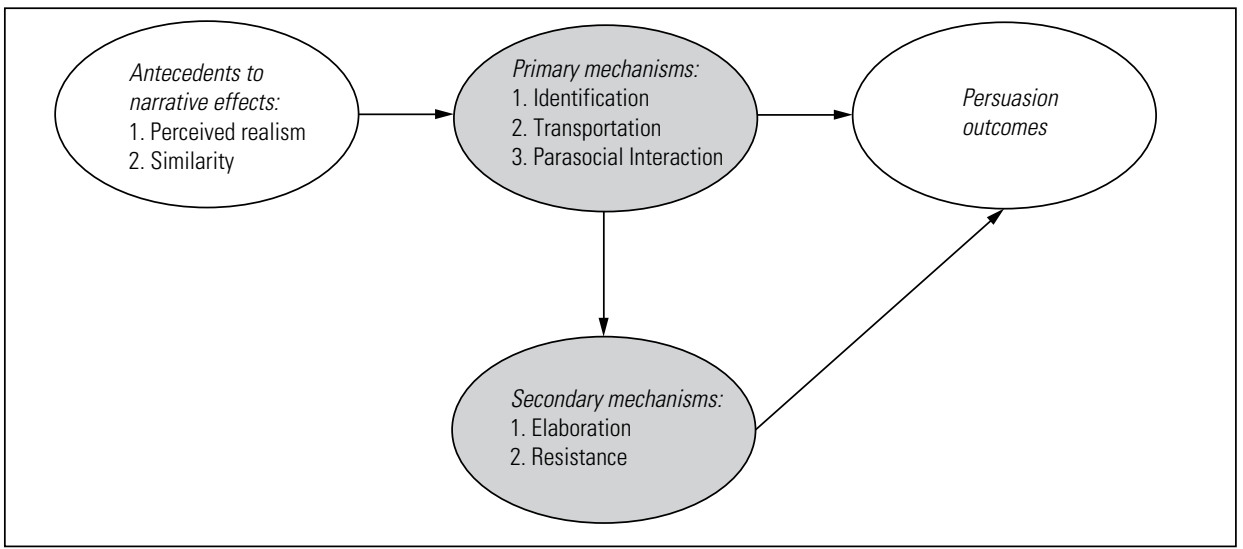

\section{Method}

\subsection{Participants and procedure}

Participants were 374 undergraduate students enrolled in introductory communication classes at the University of Georgia in the United States. Participation in the study either fulfilled students' course requirement or earned them a small portion of extra credit. The participants ranged in age from 18 to 27 years $(M=19.64$, $S D=1.34$ ), with $76.9 \%$ describing themselves as white/Caucasian, 9.4\% as of Asian descent, $3.0 \%$ as of Hispanic descent, $8.9 \%$ as of African descent and $1.6 \%$ as other. Two participants failed to disclose their race. Fifty-four percent reported their sex as female and $46 \%$ as male. Participants signed and dated consent forms before they were randomly assigned to watch one of the four video clips. At the end of the video clip, the participants completed the questionnaire, including a thought-listing task. They were debriefed and their questions answered if they had any. The data collection sessions lasted no more than 30 minutes.

\subsection{Stimuli messages}

In order to test the conceptual model, a certain amount of variance with respect to the narrative engagement variables is necessary. We therefore adopted four video clips from So and Nabi (2013), which were clips from Entourage, Sex and the City, and
Grey's Anatomy. These clips had been edited from the original aired version to specifically focus on the periods when characters were enacting or discussing sexual health. Each edited video was around nine minutes in length. The appendix presents synopses of the video clips. These four narratives varied in two dimensions: 1) gender of the main character (Male: Eric in Entourage and George in Grey's Anatomy vs. female: Miranda and Samantha in Sex and the City) and 2) Sexually transmitted diseases (STDs) symptoms (present: Miranda in Sex and the City and George in Grey's Anatomy vs. absent: Eric in Entourage and Samantha in Sex and the City). In a sense, this was an experimental $2 \times 2$ between-subjects design, with the main character's gender and STD symptoms as the manipulations. However, in this study we were not interested in the experimental manipulations, but rather to produce data with a certain amount of variances in different aspects of the narrative messages, and variances in the narrative engagement variables.

\subsection{Measures}

Confirmatory factor analyses were performed for each of the multi-item measures. Results showed that they were all uni-dimensional. All measures utilized 1-5 Likert scale items $(1=$ strongly disagree and $5=$ strongly agree) unless specified otherwise. 
Perceived realism. Perceived realism of narrative messages was measured by five items. Sample items included "The events presented in the video can actually happen in the real world" and "The situation described in the video is realistic." Responses to these items were averaged into a composite score $(M=3.89, S D=0.77$, $\alpha=.79$ ).

Perceived similarity. Perceived similarity was measured by four 1-5 point scale items $(1=$ Not at all Similar to $5=$ Very Similar). Participants were asked to judge the similarity between themselves and the characters regarding life style, daily experience, ways of interacting with other people, and sexual behavior. Responses to these items were averaged to form an overall measure of perceived similarity $(M=2.15, S D=0.94, \alpha=.84)$.

Transportation. Transportation was assessed by Green \& Brock's (2000) scale. Sample items included "While I was watching the clip, I could picture myself in the scene of the clip," and "activity around me was on my mind." Responses to these items were average into a composite score $(M=3.29, S D=0.59, \alpha=.69)$.

Identification. Identification was assessed using Cohen's (2001) scale. Ten items were used to measure the construct. Example items included "I tend to understand the reasons why the characters felt the way they did" and "When the characters succeeded I felt joy; when they failed I felt sad." Responses to these items were averaged into a composite score $(M=3.15$, $S D=0.72, \alpha=.83$ ).

Parasocial interaction. Parasocial interaction was assessed using thirteen items developed by Schramm and Hartmann (2008) ( $1=$ Strongly Disagree to $5=$ Strongly Agree). The perceptual-cognitive response exemplar questions included "Occasionally, I wondered if the characters were similar to me or not?" and "I kept wondering if I know persons that are similar to the characters?" The affective response sample questions included "Sometimes I really loved the character for what s/he did" and "If the character felt bad, I felt bad as well." The behavioral response questions included "Sometimes I felt like speaking out" and "Occasionally, I said something on impulse." Confirmatory factor analyses yielded a uni-dimensional structure after four items were dropped, resulting in a nine-item scale $(M=3.15$, $S D=0.68, \alpha=.77)$.

Perceived threat to freedom. Perceived threat to freedom was measured by four items (Dillard \& Shen, 2005). Example items included "The message threatened my freedom to choose" and "The message tried to make a decision for me." Reponses to these items were averaged into a composite score $(M=1.74, S D=0.78, \alpha=.85)$.

Psychological reactance. Psychological reactance was measured as the combination of anger and negative cognition (measures discussed below). The bivariate correlation between the two was: $r=.25$, $p<.001$. The $\mathrm{z}$-scores of anger and negative cognition were combined to create the score for psychological reactance. This construct was positively and significantly associated with perceived threat to free$\operatorname{dom}(r=.20, p<.001)$. This significant correlation demonstrated that the reactance measure was valid (Quick \& Stephenson, 2007).

Cognitive responses. Four coders, who were unaware of the hypotheses, received about 9 hours of training before they started coding $20 \%$ of the thought-listing data. Reliabilities were checked with this portion of the data only. The remainder of the data were divided among the four coders and coded by one person only. Coding procedures took place in four steps. First, the coders divided the data into psychological thought units. Guetzkow's U was around .02 for this step. Second, coders judged whether the units were cognitive or affective using a list of emotional words from Shaver, Schwartz, Kirson and O'Connor's (1987) study. Whenever those words appeared in a thought unit, it was considered as affective. Krippendorff's alpha was .78 for this step. Third, relevance of cognitive thoughts toward message were coded. Relevant thoughts were those related to message (i.e., content or delivery), or addressing risk of STD, while irrelevant thoughts were unrelated to the message or task. Krippendorff's alpha was 
.73 for this step. Fourth, the valence of thought units was coded as positive, negative, or neutral. Positive thoughts were defined as units expressing liking toward the message, agreement with message or message source, approval of intention to wear a condom or getting tested, disapproval of risky sex behaviors, and perceived impact from the message. Negative thoughts were units that expressed disliking toward the message, disagreement with message or message source, perceived irrelevance, derogation of the source, lack of intention to wear a condom or to get tested, approval of risky sex behavior, and perceived lack of impact from the message. Neutral thoughts were defined as non-evaluative responses to the message. Krippendorff's alpha was .74 for this step. Note that the valenced cognitive responses were all censored in distribution: Positive thoughts had $35.1 \%$ of the cases clustered at $0(M=1.28, S D=1.28), 40.5 \%$ of neutral thoughts $(M=1.38, S D=1.73)$ cases and $76.1 \%$ of negative thoughts $(M=0.36$, $S D=0.79$ ) cases were clustered at 0 .

Anger. Anger was measured with four 5 -point scale items $(0=$ None of this feeling and $4=$ A great deal of this feeling): irritated, angry, annoyed, and aggravated (Dillard \& Shen, 2005). These items were averaged into an index for anger $(M=0.52, S D=0.82$, $\alpha=.86$ ). It should be noted that $52 \%$ of the participants reported 0 (i.e., none of this feeling) for anger.

Elaboration. Message elaboration was assessed with Reynold's (1997) scale that consisted of 12 Likert scale items. Example items included "While watching the video I attempted to analyze the issues in the message" and "While watching the video I was deep in thought about the message." These items were averaged into an index for message elaboration such that higher scores indicated more elaboration $(M=3.38, S D=0.65, \alpha=.86)$. It should be noted that another way to measure message elaboration was to take the sum of negative and positive thoughts. However, the disadvantage of this approach was its substantive association with the reactance measure since negative cognition was a linear component of reactance, which re- sulted in multicollinearity. Therefore, the Reynold's self-report measure was used in this study. The two forms of elaboration measure were positively and significantly correlated $(r=.16, p=.004)$. This positive and significant correlation demonstrated multiple-form validity of the elaboration measure. Due to the censored distribution of cognitive response, we also examined the truncated regression coefficient (self-report onto thought-listing), which was substantially larger: $\beta=.33, \mathrm{p}=.01$.

Message perception. Message perception was measured with nine 7-point semantic differential scale items: convincing/not convincing, believable/unbelievable, and not sensible/sensible. These items were averaged into an index such that higher scores indicated more positive perception $(M=3.47, S D=1.01, \alpha=.85)$.

Risk perception. Participants were asked to estimate their own STD risk using a percentage scale ranging from $0 \%$ (not at risk at all) to $100 \%$ (extremely high risk), with $10 \%$ increments $(M=19.21 \%$, $S D=22.00 \%)$. The score was then transformed (divided by 10) to a $0-10$ scale to reduce heterogeneity.

Behavioral intention. Behavioral intention to get tested for STD within the next 6 months was measured by a single question that asked participants to provide a percentage estimate ranging from $0 \%$ (Certain that I will not) to $100 \%$ (Certain that I will), with $10 \%$ increments ( $M=20.88 \%, S D=20.94 \%)$. The score was then transformed (divided by 10) to a 0-10 scale to reduce heterogeneity.

Controlled covariates. Several variables were also measured as controlled variables in addition to the demographic variables. The participants were asked to report in the past year 1) if they have been sexually active (67\% yes); if yes 2$)$ how many sex partners they had $(M=1.85$, $S D=3.07) ; 3)$ if they practiced safe sex $(54 \%$ reported yes); and 4) if they got tested for STDs (16\% reported yes). 
Table 1: $\quad$ Means, standard deviations, and correlation matrix of variables $(\mathrm{N}=374)$

\begin{tabular}{|c|c|c|c|c|c|c|c|c|c|c|c|c|}
\hline Variables & Mean & S.D. & 1 & 2 & 3 & 4 & 5 & 6 & 7 & 8 & 9 & 10 \\
\hline 1. Transportation & 3.27 & 0.60 & 1.00 & & & & & & & & & \\
\hline 2. Identification & 3.15 & 0.70 & .61 & 1.00 & & & & & & & & \\
\hline 3. Parasocial interaction & 3.15 & 0.70 & .65 & .62 & 1.00 & & & & & & & \\
\hline 4. Reactance & 0.00 & 1.34 & -.04 & -.08 & -.03 & 1.00 & & & & & & \\
\hline 5. Elaboration & 3.38 & 0.67 & .56 & .39 & .41 & .04 & 1.00 & & & & & \\
\hline 6. Message perception & 3.53 & 0.96 & .42 & .41 & .32 & -.23 & .04 & 1.00 & & & & \\
\hline 7.Perceived risk & 1.92 & 2.30 & .18 & .16 & .17 & .04 & .05 & .13 & 1.00 & & & \\
\hline 8. Intention to get tested & 2.09 & 3.00 & .12 & .11 & .06 & .04 & -.01 & .11 & .36 & 1.00 & & \\
\hline 9. Realism & 3.89 & 0.75 & .31 & .27 & .17 & -.25 & .00 & .61 & .14 & .09 & 1.00 & \\
\hline 10. Similarity & 2.15 & 0.94 & .26 & .36 & .35 & -.07 & -.04 & .30 & .29 & .08 & .19 & 1.00 \\
\hline
\end{tabular}

\section{Results}

\subsection{Input data and SEM model specification}

Since the hypotheses and the research question involved two exogenous variables, a set of mediating variables, and persuasion outcomes (message perception, risk perception and intention to get tested for STDs), the strategy of structural equation modeling (SEM) was adopted. Table 1 presents the means, standard deviations, and correlation matrix (with demographic variables and the four covariates partialled out) of the major variables. These data were entered to LISREL 8.80 as the input for the SEM analyses. Specifically, 1) realism and similarity were specified to have paths to transportation, identification, and parasocial interaction. 2) Due to the conceptual closeness, transportation, identification, and parasocial interaction were allowed to correlate. 3) These three variables were specified to predict reactance and message elaboration, and the persuasion outcomes (message perception, perceived risk, and intention to get tested). 4) Reactance and message elaboration were specified to predict the three persuasion outcomes, but no association was allowed between the two. Finally, 5) message perception and perceived risk were specified to predict intention to get tested for STDs.

\subsection{The obtained model}

To evaluate the overall model fit, four indices were considered: the Goodness of
Fit Index (GFI), the Comparative Fit Index (CFI), the Root Mean Square Error of Approximation (RMSEA), and the Bayesian Information Criterion (BIC). BIC is constructed such that negative values provide evidence of model fit, while positive BIC values suggest problematic model fit. Differences in BIC of 2 or more provide evidence favoring one model (with the smaller BIC value) over another; 6 or more provide strong evidence; and 10 is taken to be very strong evidence for model improvement (Raftery, 1995). With nonsignificant paths removed, the original model did not fit to the data: $\chi^{2}(25)=213.59, p<.001, \mathrm{GFI}=0.91$, $\mathrm{CFI}=0.88$, RMSEA $=0.13, \mathrm{BIC}=65.48$. Two paths were added post hoc, but based on existing empirical evidence: A path from realism to message perception (Cho et al., 2014) and a path from similarity to perceived risk (So \& Nabi, 2013). That resulted in a model with acceptable fit to the data: $\chi^{2}(23)=84.24, p<.001, \mathrm{GFI}=0.96$, $\mathrm{CFI}=0.96, \quad \mathrm{RMSEA}=0.08, \quad \mathrm{BIC}=-52.02$. Figure 2 presents the standardized path coefficients in the obtained model. We turn to the path coefficients for hypothesis testing and answering the research question.

The first two hypotheses predicted that realism and similarity would be positively associated with the narrative engagement variables. The obtained model showed that realism had a positive and significant path to transportation $(\beta=.11, p<.001)$, to identification $(\beta=.27, p<.001)$, and to parasocial interaction $(\beta=.27, p<.001)$. Therefore, $\mathrm{H} 1$ received support. Similarity 
Figure 2: Standardized path coefficients in the obtained model

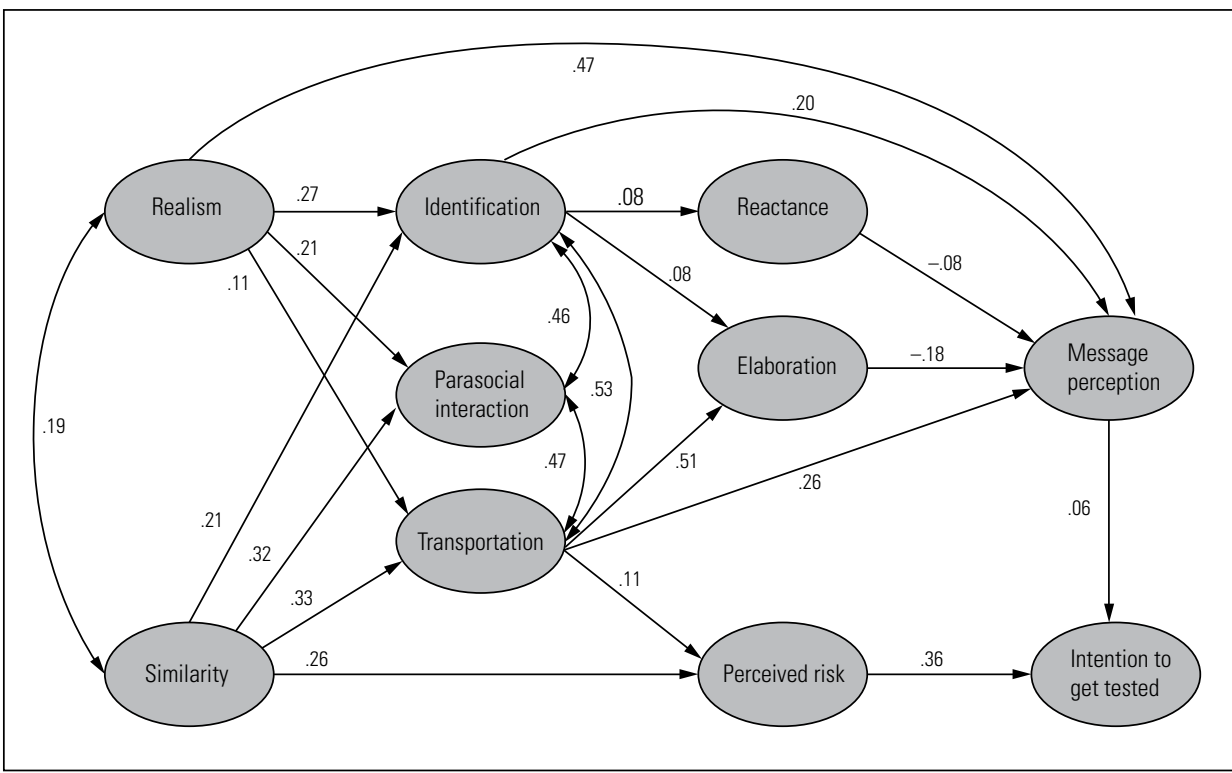

Note. All paths were significant at $p<.05$.

also had a positive and significant path to transportation $(\beta=.33, p<.001)$, to identification $(\beta=.21, p<.001)$, and to parasocial interaction $(\beta=.32, p<.001)$. H2 also received support.

Hypotheses 3-6 and the research question were concerned with the direct effect of various forms of narrative engagement on persuasion outcomes, and their indirect effects through counterarguments and message elaboration. Recall that psychological reactance was measured as the combination of counterarguments and anger. This meant that hypotheses that involved counterarguments (H3b, H4b, and H5b) were subsumed by the hypothesis that involved reactance. Therefore, H3b-5b were tested with reactance instead of counterarguments; and these three hypotheses combined sufficed testing of H6. The obtained model showed that transportation had a positive and significant path to message perception $(\beta=.26, p<.001)$ and to perceived risk $(\beta=.11, p=.01)$, which in turn had positive paths to intention $(\beta=.06, p=.04$ from message perception, and $\beta=.36$, $p<.001$ from perceived risk respectively).
These paths demonstrated the direct effect from transportation on persuasion. H3a received support. There was no significant path from transportation to psychological reactance. H3b did not receive support. The path from transportation to message elaboration was positive and significant $(\beta=.51, p<.001)$; and the path from message elaboration to message perception was negative and significant $(\beta=-.18, p<.001)$. These two paths showed that transportation had an indirect effect on message perception through message elaboration, but it was in the opposite direction predicted by H3c. Therefore, H3c did not receive support.

There was a positive and significant path from identification to message perception $(\beta=.20, p<.001)$, but no significant path from identification to perceived risk. These results showed some, but not strong evidence for H4a. There was a negative and significant path from identification to reactance $(\beta=-.08, p=.03)$, which in turn had a negative and significant impact on message perception $(\beta=-.08, p=.03)$. $\mathrm{H} 4 \mathrm{~b}$ received support. There was a positive and significant path from identification to 
message elaboration $(\beta=.08, p=.03)$. Due to the negative impact of message elaboration on message perception, $\mathrm{H} 4 \mathrm{c}$ did not receive support. There was no significant path emerging from parasocial interaction, which meant that H5a and H5b did not receive support, and there was no impact from parasocial interaction on message elaboration (RQ). Overall, only one of the three narrative engagement variables had a negative impact on psychological reactance; therefore, there was some, but not strong evidence for $\mathrm{H} 6$.

\section{Discussion}

Consistent with the extant literature, results from the current study yielded strong evidence that both realism and similarity enhanced narrative engagement. There has been empirical evidence on the message features that would increase perceived realism (Cho et al., 2014; Shapiro \& Kim, 2012). On the other hand, perceived similarity increases when individuals perceive to hold features that match with the characters' features, including appearance, demographic information, and experience. This means that enhancing perceived similarity through matching can be a way to create effective and efficient realistic narrative messages, such that narrative engagement would be enhanced to facilitate the persuasion of the target audience. This means that there are effective and efficient means to create realistic narrative messages, with characters' features matching the target audience members' features such that narrative engagement would be enhanced to facilitate the persuasion purpose.

Such a practical utility is contingent upon the direct and indirect effects that various forms of narrative engagement have on persuasion. Indeed, results from the current study showed that 1) there was direct effect from transportation on persuasion, 2) direct effect from identification on message perception, and 3) indirect effect from identification on message perception through reducing reactance. On the other hand, there were also results inconsistent and even opposite to the hypotheses: 1) Parasocial interaction did not have any impact, direct or indirect, on persuasion outcomes. 2) Although transportation and identification had positive impact on elaboration; elaboration had a negative effect on message perception, which meant the indirect effects via elaboration were actually counter-persuasion. And 3) there were effects from realism and similarity that were not mediated by narrative engagement.

The lack of effect from parasocial interaction on persuasion should not mean parasocial interaction is not important in the process and effect of narrative communication. The substantial correlations among transportation, identification, and parasocial interaction meant that the lack of significant paths from parasocial interaction reflected the absence of unique impact from parasocial interaction on persuasion. That is, the impact of parasocial interaction probably have overlapped with that from transportation and/or identification. It is likely that significant effect from parasocial interaction would have been detected if not all three forms of narrative engagement had been studied, or when parasocial interaction had been the single form of narrative engagement under investigation in a particular study. As a matter of fact, a meta-analysis already provided evidence for such effects, which was based on the bivariate association between parasocial interaction and media effects (Schiappa et al., 2007). Of course, sampling error always remains a potential explanation. The moderate size of the associations among the three primary forms of narrative engagement also means that they are both conceptually and empirically distinct from each other and most likely need to be treated as separate mechanisms.

The negative association between elaboration and message perception was exactly opposite of the hypotheses. This finding means that elaboration predicted resistance to persuasion, which was inconsistent with either theory or extant empirical evidence. One explanation might lie in the entertainment-education dialec- 
tic inherent in narrative communication. Elaboration on the education information would facilitate persuasion. However, elaboration on entertainment information tends to be unrelated to persuasive points, objectionable in some way and inconsistent with the persuasive information and/ or advocacy (Bilandzic \& Busselle, 2013). When that happens, elaboration would overlap with counterarguments, which could result in resistance. The thought-listing data in this study suggested that it might have been the case, particularly when the participants were elaborating on the number of sex partners the characters had, and the differential social perceptions of male vs. female when one has a large number of sex partners.

The direct effects from perceived realism and similarity on persuasion were not surprising, given that there was already empirical evidence (Cho et al., 2014; So \& Nabi, 2013). Theoretically, this meant that the impact from narrative messages on persuasion outcomes might not be entirely mediated by narrative engagement. That is, narrative impact might take place in a more superficial and heuristic way, without much cognitive engagement. On the other hand, such effects are in the same direction of the effects proposed in the existing theories and models of narrative communication. In other words, they were compatible with each other.

The aforementioned effects and processes have to be interpreted with the limitations of the current study in mind. The first major limitation lied in the lack of a control condition, that is, a non-narrative message condition. Although the non-narrative control was not essential in the current study since our theoretical focus was not to investigate the effect of narrative vis-à-vis non-narrative messages, the lack of contrast inevitably resulted in restriction in range in at least some major variables, most saliently in resistance -both counterarguments and anger were severely censored in distribution. Such censored distributions meant that the paths involving reactance might have been under-estimated in SEM analyses (e.g., Shen \& Dillard, 2009), which could have been the reasons for the weak evidence for the overcoming resistance hypotheses. Future studies should strive to investigate both the persuasive edge that narratives have over non-narratives and the underlying mechanisms at the same time. The second limitation was there was little variability in the ratio of entertainment vs. education information across the four narratives. Bilandzic and Busselle (2013) suggested that the persuasive impact of a narrative might be a function of 1) how well the entertainment information and the education information were integrated and 2) how explicit the persuasive point was in the narrative. There is reason to believe that both persuasive outcomes and the form and nature of narrative engagement that underlie persuasion would be affected when the ratio of education information changes relative to entertainment information (e.g., a 30 second PSA presented as a narrative vs. long video messages designed to entertain). Future studies that manipulate this dimension of narrative messages should further our understanding of the nature of narrative communication. The third limitation was that all four narratives were on the same health topic of STDs. The advantage of this topic came from its relevance to the college student sample. The disadvantage was that it reduced the generalizability and external validity of the findings. Lastly, although the content of the original TV shows and the topic of STDs were relevant and involving to college students, the use of such a sample limits the external validity of the findings. Future studies that utilize more topics and more narratives using samples from the general public would be at a better position to further our understandings of narrative communication.

\section{Conclusion}

We set out to simultaneously test a comprehensive list of narrative engagement variables as the primary and secondary psychological mechanisms that underlie the persuasive effects from narrative messages. The obtained model from SEM anal- 
yses supported such a model in general. Identification, transportation, and parasocial interaction are the primary mechanisms, and message elaboration and (overcoming) resistance are the secondary mechanisms. The findings are consistent with studies that investigate some of the variables investigated here (i.e., only part of a comprehensive model). While the individual hypotheses tested here might not be novel, our study tested the hypotheses simultaneously and against each other for the first time. This offers insight into their unique contributions to narrative persuasion, and helps to explain inconsistencies regarding the individual factors in the literature.

\section{References}

Antonakis, J., Bendahan, S., Jacquart P., \& Lalive, R. (2010). On making causal claims: A review and recommendations. The Leadership Quarterly, 21, 1086-1120. doi: 10.1016/j.leaqua.2010.10.010

Appel, M., \& Richter, T. (2010). Transportation and need for affect in narrative persuasion: A mediated moderation model. Media Psychology, 13, 101-135. doi: $10.1080 / 15213261003799847$

Bandura, A. (2001). Social cognitive theory of mass communication. In J. Bryant, \& D. Zillmann (Eds.). Media effects: Advances in theory and research ( $2^{\text {nd }}$ ed., pp. 121-153). Hillsdale, NJ: Lawrence Erlbaum.

Basil, M. D. (1996). Identification as a mediator of celebrity effects. Journal of Broadcasting \& Electronic Media, 40, 478-495.

Berger, C., \& Lee, K. J. (2011). Second thoughts, second feelings: Attenuating the impact of threatening narratives through rational reappraisal. Communication Research, 38, 3-26. doi: 10.1177/0093650210377986

Bilandzic, H., \& Busselle, R. (2013). Narrative persuasion. In J. P. Dillard \& L. Shen (Eds.), The Sage handbook of persuasion: Developments in theory and practice ( $2^{\text {nd }} \mathrm{ed}$.) (pp. 200-219). Los Angeles, CA: Sage.

Braddock, K., \& Dillard, J.P. (2016). Meta-analytic evidence for the persuasive effect of narratives on beliefs, attitudes, intentions, and behaviors. Communi- cation Monographs, 83, 446-467. doi: 10.1080/03637751.2015.1128555

Brehm, J.W. (1966). A theory of psychological reactance. New York: Academic Press.

Brehm, S. S., \& Brehm, J.W. (1981). Psychological reactance: $A$ theory of freedom and control. New York: Academic Press.

Busselle, R.W., \& Bilandzic, H. (2008). Fictionality and perceived realism in experiencing stories: A model of narrative comprehension and engagement. Communication Theory, 18, 255-280. doi: 10.1111/j.14682885.2008.00322.x

Cacioppo, J.T., \& Petty, R.E. (1981). Social psychological procedures for cognitive response assessment: The thought-listing technique. In T.V. Merluzzi, C. R. Glass, \& M. Genest (Eds.), Cognitive assessment (pp. 309-342). New York, NY: Guilford.

Campbell, M.W., \& de Waal, F. B. (2011). Ingroup-outgroup bias in contagious yawning by Chimpanzees supports link to empathy. PLoS ONE, 6, e18283. doi:10.1371/ journal.pone.0018283

Campbell, R. G., \& Babrow, A. S. (2004). The role of empathy arousal in responses to persuasive health communication. Health Communication, 16, 159-182. doi: 10.1207/S15327027HC1602_2

Chaiken, S., Liberman, A., \& Eagly, A. H. (1989). Heuristic and systematic processing within and beyond the persuasion context. In J. S. Uleman \& J. A. Bargh (Eds.), Unintended thought (pp. 212-252). New York, NY: Guilford Press.

Cho, H., Shen, L., \&Wilson, K. (2014). Perceived realism: Examining its dimensions and roles in narrative persuasion. Communication Research, 41, 828-851. doi: 10.1177/0093650212450585

Cohen, J. (2001). Defining identification: A theoretical look at the identification of audiences with media characters. Mass Communication \& Society, 4, 245-264.

Dal Cin, S., Zanna, M. P., \& Fong, G.T. (2004). Narrative persuasion and overcoming resistance. In E.S. Knowles, \& J.A., Linn (Eds.). Resistance and persuasion (pp. 175-191). Mahwah, NJ: Lawrence Erlbaum Associates.

DeGeorge, J., \& Constantino, M. J. (2012). Perceptions of analogue therapist empathy as a function of salient experience similarity. 
Journal of Psychotherapy Integration, 22, 52-59. doi: 10.1037/a0027365

Dillard, J.P., \& Shen, L. (2005). On the nature of reactance and its role in persuasion. Communication Monographs, 72, 144-168. doi: 10.1080/03637750500111815

Durkin, S., \& Wakefield, M. (2008). Interrupting a narrative transportation experience: Program placement effects on responses to antismoking advertising. Journal of Health Communication, 13, 667-680. doi: $10.1080 / 10810730802412248$

Escalas, J.E. (2007). Self-referencing and persuasion: Narrative transportation versus analytical elaboration. Journal of Consumer Research, 33, 421-429.

Escalas, J.E. (2004a). Imagine yourself in the product: Mental stimulation, narrative transportation, and persuasion. Journal of Advertising, 33, 37-48.

Escalas, J.E. (2004b). Narrative processing: Building consumer connections to brands. Journal of Consumer Psychology, 14, 168-180.

Fisch, S. M. (2000). A capacity model of children's comprehension of educational content on television. Media Psychology, 2, 63-91. doi:10.1207/S1523785XMEP0201_4

Fisher, R. J. (1998). Group-derived consumption: The role of similarity and attractiveness in identification with a favorite sports team. Advances in Consumer Research, 25, 283-288.

Green, M.C. (2004). Transportation into narrative worlds: The role of prior knowledge and perceived realism. Discourse Processes, 38, 247-266. doi: 10.1207/ s15326950dp3802_5

Green, M.C. (2007). Linking self and others through narrative. Psychological Inquiry, 18, 100-102. doi:10.1080/10478400701416152

Green, M. C., \& Brock, T. C. (2000). The role of transportation in the persuasiveness of public narratives. Journal of Personality and Social Psychology, 79, 701-721. doi: 10.1037/0022-3514.79.5.701

Gueguen, N., \& Martin, A. (2009). Incidental similarity facilitates behavioral mimicry. Social Psychology, 40, 88-92. doi: $10.1027 / 1864-9335.40 .2 .88$

Hall, A. (2003). Reading realism: Audiences' evaluations of the reality of media texts.
Journal of Communication, 53, 624-641. doi: 10.1111/j.1460-2466.2003.tb02914.x

Hall, L., \&Woods, S. (2006). The importance of similarity in empathic interaction. In C. Ghaoui (Ed.), Encyclopedia of human computer interaction (pp. 303-310). Hershey, PA: IGI Publishing.

Hinyard, L. J., \& Kreuter, M.W. (2007). Conceptual, theoretical, and empirical overview of narrative communication. Health Education and Behavior, 34(5), 777-792.

Hoffner, C., \& Buchanan, M. (2005). Young adults' wishful identification with television characters: The role of perceived similarity and character attributes. $\mathrm{Me}$ dia Psychology, 7, 325-351. doi: 10.1207/ S1532785XMEP0704_2

Igartua, J. (2010). Identification with characters and narrative persuasion through fictional feature films. Communications - The European Journal of Communication Research, 35, 347-373.

Kelman, H. (1961). Processes of opinion change. The Public Opinion Quarterly, 25, 57-78.

Krakowiak, K., M., \& Oliver, M. B. (2012). When good characters do bad things: Examining the effect of moral ambiguity on enjoyment. Journal of Communication, 62, 117135. doi:10.1111/j.1460-2466.2011.01618.x

Kreuter, M.W., Green, M. C., Cappella, J. N., Slater, M. D., Wise, M. E., Storey, D., Clark, E. M., O'Keefe, D. J., Erwin, D. O., Holmes, K., Hinyard, L. J., Houston, T., \& Wooley, S. (2007). Narrative communication in cancer prevention and control: A framework to guide research and application. Annals of Behavioral Medicine, 33, 221-235. doi: 10.1007/BF02879904

Krippendorff, K. (2004). Reliability in content analysis: Some common misconceptions and recommendations. Human Communication Research, 30, 411-433. doi: 10.1111/j.1468-2958.2004.tb00738.x

Moyer-Gusé, E., Chung, A. H., \& Jain, P. (2011). Identification with characters and discussion of taboo topics after exposure to an entertainment narrative about sexual health. Journal of Communication, 61,387-406. doi: 10.1111/j.14602466.2011.01551.x

Moyer-Gusé, E., \& Nabi, R. L. (2010). Explaining the persuasive effects of narrative in an 
entertainment television program: Overcoming resistance to persuasion. Human Communication Research, 36, 25-51. doi: 10.1111/j.1468-2958.2009.01367.x

Murphy, S.T., Frank, L. B., Chaterjee, J. S., \& Baezconde-Garbanati, L. (2013). Narrative versus nonnarrative: The role of identification, transportation, and emotion in reducing health disparities. Journal of Communication, 63, 116-137. doi: 10.1111/ jcom. 12007

Oatley, K. (1996). Inference in narrative and science. In D. R. Olson \& N. Torrance (Eds.), Modes of thought: Explorations in culture and cognition (pp. 123-140). New York: Cambridge University Press.

Perse, E. M., \& Rubin, R. B. (1989). Attribution in social and parasocial relationships. Communication Research, 16, 59-77.

Petty, R.E., \& Cacioppo, J.T. (1986). The elaboration likelihood model of persuasion. In Berkowitz (Ed.), Advances in experimental social psychology, vol. 19 (pp. 123-205). San Diego, CA: Academic Press.

Quick, B., \& Stephenson, M. (2007). Further evidence that psychological reactance can be modeled as a combination of anger and negative cognitions. Communication Research, 34, 255-276. doi: 10.1177/0093650207300427

Raftery, A.E. (1995). Bayesian model selection in social research. In P.V. Marsden (Ed.), Sociological methodology (pp. 111-163). Cambridge: Basil Blackwell.

Reynolds, R.A. (1997). A validation test of a message elaboration measure. Communication Research Reports, 14, 269-278.

Schiappa, E., Allen, M., \& Gregg, P. B. (2007). Parasocial relationships and television: A meta-analysis of the effects. In R.W. Preiss, B. M., Gayle, N. Burrell, M. Allen, \& J. Bryant (Eds.). Mass media effects research: Advances through meta-analysis (pp. 301-314). Mahwah, NJ: Lawrence Erlbaum Associates.

Schramm, H., \& Hartmann, T. (2008). The PSI-process scales: A new measure to assess the intensity and breadth of parasocial processes. Communications-European Journal of Communication Research, 33, 385-401.

Selfhout, M., Denissen, J., Branje, S., \& Meeus, W. (2009). In the eyes of the beholder:
Actual, and peer-rated similarity in personality, communication, and friendship intensity during the acquaintanceship process. Journal of Personality and Social Psychology, 96, 1152-1165. doi: 10.1037/ a0014468

Shapiro, M., \& Kim, H. (2012). Realism judgment and mental resources: A cue processing model of media narrative realism. Media Psychology, 15, 93-119. doi: 10.1080/15213269.2011.649666

Shen, F., Sheer, V.C., \& Li, R. (2015). Impact of narratives on persuasion in health communication: A meta-analysis. Health Communication, 44, 105-113. doi: 10.1080/00913367.2015.1018467

Shen, L. (2010). Mitigating psychological reactance: The role of message-induced empathy in persuasion. Human Communication Research, 36, 397-422. doi: 10.1111/j.1468-2958.2010.01381.x

Shen, L., \& Dillard. J.P. (2009). Message frames interact with motivational systems to determine depth of message processing. Health Communication, 24, 504-514. doi: 10.1080/10410230903104897

Slater, M. D., \& Rouner, D. (2002). Entertainment-education and elaboration-likelihood: Understanding the processing of narrative persuasion. Communication Theory, 12, 173-191. doi: 10.1111/j.14682885.2002.tb00265.x

So, J., \& Nabi, R. (2013). Reduction of perceived social distance as an exploration for media's influence on personal risk perceptions: A test of the risk convergence model. Human Communication Research, 39, 317-338. doi:10.1111/hcre.12005

Steensma, H., \& Erkel, D. (1999). Reactance to perceived external pressure to introduce quality assurance standards in organizations. Psychological Reports, 85, 1077-1080.

van Laer, T., Ruyter, K. D., Visconti, L. M., \& Wetzels, M. (2014). The extended transportation-imagery model: A meta-analysis of the antecedents and consequences of consumers' narrative transportation. Journal of Consumer Research, 40, 797-817. doi: 10.1086/673383.

Zillmann, D. (2002). Exemplification theory of media influence. In J. Bryant \& D. Zillmann (Eds.), Media effects: Advances in 
theory and research ( $2^{\text {nd }}$ ed., pp. 19-41). Mahwah, NJ: Erlbaum.

Zillmann, D., \& Knobloch, S. (2001). Emotional reactions to narratives about the fortunes of personae in the news theater. Poetics, 29, 189-206.

\section{Appendix: Synopses of stimuli video clips}

Video 1: In Entourage, Eric's friends tell him that a girl he is interested in previously dated his friend Drama. Drama reveals to Eric that he thinks the girl has an STD and that Eric should be tested immediately. After hearing this, Eric reluctantly goes to the doctor to be tested.

Video 2: In Sex and the City, Miranda is diagnosed with chlamydia. She is told to contact all her recent sexual partners and has a great conversation with Steve, her partner, about why he needs to be tested, even though he doesn't have any symptoms.

Video 3: In Grey's Anatomy, George asks Alex to take a look at this strange rash that he has, which he discovers is syphilis. The only person George has been with is Olivia, the nurse he's dating, and he has to confront her about contracting STD.

Video 4: In Sex and the City, Samantha considers getting an STD test when a man refuses to sleep with her until she has been tested. She reveals that the main reason she hasn't taken the test is because she's afraid of what the results may be.

\section{Acknowledgements}

We thank Dr. Jiyeon So and Dr. Robin Nabi for their generosity in sharing the stimuli videos used in this study. 
